\title{
Erratum to: The Evolutions of Medical Building Network Structure for Emerging Infectious Disease Protection and Control
}

\author{
Nan Liu $\cdot$ Hongzhe Zhang $\cdot$ Shanshan Zhang
}

Published online: 16 October 2014

(c) Springer Science+Business Media New York 2014

\section{Erratum to: Cell Biochem Biophys}

DOI 10.1007/s12013-014-0123-1

Unfortunately the second author's name was not displayed in the original publication of the article. Additionally, there are few changes in the order of authors, article correspondence, and affiliations. The corrected details of the authors and their affiliations are presented in this erratum.

Nan Liu and Hongzhe Zhang contributed equally to this work and are joint first authors.

The online version of the original article can be found under doi:10.1007/s12013-014-0123-1.

N. Liu $\cdot$ H. Zhang $\cdot$ S. Zhang $(\bowtie)$

School of Architecture, Harbin Institute of Technology, 92 West

Dazhi Street, Nan Gang District, Harbin 150001, China

e-mail: drshanshanzhang@163.com

N. Liu

School of Civil Engineering, Northeast Forestry University, No.

26 Hexing Road, Xiangfang District, Harbin 150040, China

H. Zhang

College of Civil Engineering and Architecture, Harbin

University of Science and Technology, Nangang District, No. 52

Xuefu Road, Harbin 150080, China 